\title{
PERMAINAN ALAT MUSIK VIUL DALAM KESENIAN KRINOK DI MUARO BUNGO PROVINSI JAMBI DITINJAU DARI TEORI POSKOLONIAL
}

\author{
Achmad Junaidi \\ Pascasarjana Institut Seni Indonesia Padangpanjang, Indonesia \\ Email: Junaidiviol@gmail.com, HP 085381883718
}

\begin{abstract}
This article discusses the playing of the viul musical instrument in the krinok art in Muaro Bungo, Jambi Province, which is one of the provinces in Indonesia that was once occupied by a colonial nation. The research was directed to show the impact of the colonization in the form of traces that are still remaining today, in this case in the context of the krinok art. Applying qualitative research methods, the data is carried out through observation and interviews of one of the traditional artists, namely Zulkarnain, one of the viul players. Making use of concepts from postcolonial theory, which shows the impact of the impact of the meeting of different cultures, which produces a new space with an identity that is hybrid and ambivalent.
\end{abstract}

Keywords: Zulkarnain; viul; krinok; postcolonial.

\begin{abstract}
ABSTRAK
Artikel ini membahas tentang permainan alat musik viul dalam kesenian krinok di Muaro Bungo Provinsi Jambi, yang merupakan salah satu propinsi di Indonesia yang pernah diduduki oleh bangsa penjajah. Penelitian diarahkan untuk menunjukkan dampak penjajahan tersebut berupa jejak-jejak yang masih tersisa hingga sekarang, dalam hal ini pada konteks kesenian krinok. Menerapkan metode penelitian kualitatif, pengumpulan data dilakukan melalui observasi dan wawancara terhadap salah satu seniman tradisi yaitu Zulkarnain sebagai salah satu pemain viul. Memanfaatkan konsep-konsep dari teori poskolonial, penelitian menunjukkan adanya dampak dari bertemunya budaya-budaya yang berbeda, yang menghasilkan suatu ruang yang baru dengan munculnya identitas yang baru yang bersifat hibrid dan ambivalen.
\end{abstract}

Katakunci: Zulkarnain, viul, krinok, poskolonial.

\section{PENDAHULUAN}

Propinsi Jambi merupakan salah satu propinsi yang berbudaya Melayu. Banyak kesenian yang lahir di propinsi Jambi seperti, krinok, senandung jolo, mantau, doak, berdah dan masih banyak lagi yang lainnya. Beberapa perkembangannya kesenian ini telah banyak berubah sebagaimana bentuk kesenian yang aslinya. Salah satunya adalah kesenian krinok, sebagai sebuah bentuk kesenian, krinok pada awalnya 
merupakan seni vokal yang sangat sederhana, krinok hanya berupa puisi lama yang dinyanyikan sedemikian rupa dengan nada-nada tinggi dan tanpa alat musik. Beberapa perkembangan selanjutnya, kesenian krinok tidak lagi berupa bentuk kesenian vokal saja namun sudah berkembang dalam bentuk penambahan-penambahan alat musik. Beberapa alat musik mulai dipadukan untuk mengiring krinok, seperti gong, gendang panjang dan viul. Ketiga alat musik tersebut kemudian menjadi pakem bagi musik pengiring krinok.

Viul adalah sebuah alat musik dawai yang dimainkan dengan cara digesek dengan menggunakan bowing, dan mempunyai empat buah senar yang masing-masing senar ber-nada EA-D-G. Secara bentuk viul itu sendiri adalah alat musik violin, namun bagi masyarakat Jambi biola itu sendiri lebih dikenal dengan sebutan viul. Masuknya instrument viul ini ke daerah Jambi masih belum bisa dipastikan. Berdasarkan sejarahnya alat musik biola dibawa oleh orangorang Portugis (Eropa), yang bertempat tinggal dan menetap di wilayah malasyia, kemudian alat musik biola ini menyebar ke wilayah kebudayaan lainnya di sepanjang koloni jajahan Eropa seperi Sumatera, Jawa, Maluku, Kalimantan, Sulawesi dan yang lainnya (Zulfahmi. 2016;15).

Melihat dari sejarah yang ada, peneliti mencoba melihat dari aspekaspek sejarah, yang mana peneliti mencoba mempelajari serta melihat sebuah kesenian melalui disipilin keilmuan postkolonial. Teori poskolonial dapat dikatakan sebagai teori yang digunakan sebagai alat analisis untuk menggugat praktekpraktek kolonialisme bentuk baru yang telah melahirkan kehidupan yang penuh dengan rasisme, hubungan kekuasaan yang tidak seimbang, budaya subaltern, hibriditas dan kreofisasi bukan dengan propaganda peperangan dan kekerasan fisik, tetapi didialektikakan melalui kesadaran atau gagasan (Martono, 2002: 29).

Zulkarnain adalah salah seorang pemain viul di Sanggar Tradisi Pinang Selayang kota Jambi, dan sudah mulai bermain musik pada tahun 1990-an di Muaro Bungo, dengan memainkan alat musik gambus. Pada tahun 1993 Zulkarnain mulai mempelajari alat musik viul namun masih dengan menggunakan gaya permainan tradisi, seiring perkembangannya Ia mulai belajar viul dengan gaya konvensional yang ia pelajari secara otodidak pada tahun 1995 (Zulkarnain, 11 November 2017).

Zulkarnain sendiri sebagai pelaku dalam permainan viul tanpa disadari telah mencoba memperlakukan alat musik violin seperti alat musik tradisi Jambi sendiri sehingga permainan viul Zulkarnain telah lepas dari permainan violin yang sebagaimana dimainkan di barat. Peneliti melihat disinilah terjadinya proses mimikri. Meniru tidak berarti meniru (sepenuhnya) mengekor, karena dalam meniru (mimicry) sering terkandung unsur mengejek (Mockery). Meniru adalah tindakan mengagumi sekaligus melawan (Budiawan, 2010; xii). Proses peniruan tersebut bukanlah tindakan plagiarisme semata, karna dalam proses peniruan ini Zulkarnain tidak sepenuhnya meniru sebuah objek dengan seutuhnya, hasil dari mimikri inilah menimbulkan sebuah identitas yang baru bagi subjek yang melakukan peniruan.

Viul sendiri adalah alat musik yang sering dimainkan untuk 
membawakan lagu-lagu Melayu atau lagu tradisi Jambi, seperti Krinok, Rampi Rampo dan Serampang Laut. Sebagai kesenian sastra daerah yang pada awalnya hanya dimainkan hanya dengan vokal, kesenian-kesenian tersebut sekarang sudah ditambahkan dalam bentuk instrument yang bukan dari daerah dari propinsi Jambi, melainkan instrument yang datang dari daerah luar. Pengaruh-pengaruh yang datang tersebut meninggalkan jejak keberadaan masa lampau yang masih bisa terlihat sampai saat ini. Perpaduan kesenian yang dihasilkan dari dampak pengaruh kolonial juga menjadikan perpaduan dalam kebudayaan-kebudayaan yang berbeda, sehingga kebudayaan tersbut berbaur bahkan bercampur dengan kebudayaan yang asli dengan kebudayaan yang datang, yang disebakan oleh penjajahan atas masa lampau.

Sikap ambivalen yang dilakukan Zulkarnain muncul sebagai fakta atas masuknya pengaruh-pengaruh dua budaya yang bertemu, atau menjadi hibrid. Sehingga, dalam dua pertemuan itu dua kebudayaan yang berbeda tadi dapat melebur dan memunculkan 'kebaruan yang berasal dari keduanya. Realitas yang hibrid itu, yang berproses dari dan bergerak bersama hubungan ulang-alik sekaligus ambivalen antara yang modern dan tradisional, yang global dan lokal, yang Barat dan non-Barat, tak bisa (dan karena itu tak perlu) diatasi dengan penanggulangan. Setiap upaya penanggulangan adalah satu bentuk kekerasan. (Budiawan. Ambivalensi. 2010; xvii).

Pada awalnya zulkarnain memainkan viul dengan gaya tradisi, karena dalam permainan viul ini hanya memainkan beberapa repertoar saja sehingga teknik permainan tradisipun hanya seperti itu saja. Untuk memainkan viul dengan posisi tradisi senar/tali yang lebih sering dimainkan hanya tiga senar walaupun senar yang terpasang tetap empat buah senar. Karena dalam permainan tradisi pada saat itu hanya sedikit menggunakan teknik-teknik permainan biola pada umumnya atau konvensional. Namun dengan berkembangnya, Zulkarnain mulai memainkan viul dengan gaya konvensional atau dengan gaya-gaya biola Eropa pada umumnya.

Bahwa akibat dari penjajahan atau kolonial antara penjajah dan terjajah masing-masing tidak bisa merepresentasikan budaya mereka secara murni atau bahasa mereka secara murni. Mereka saling tergantung satu sama lain, sehingga melahirkan budaya hibriditas atau budaya campuran. Hal ini mengakibatkan identitas budaya selalu berada dalam wilayah kontradiksi dan ambivalensi atau "ruang ketiga" sehingga pengakuan terhadap sebuah hirarki "kemurnian" budaya menjadi tidak dapat dipertahankan lagi (Bhaba,1994: 24).

Zulkarnain dalam permainannya mencoba memiankan viul dengan menggunakan teknik yang dipelajari secara otodidak, dan mengembangkan tekniknya sendiri dengan menggunakan media yang bukan dari daerah Jambi. Zulkarnain belajar memainkan viul atas dasar telah bisa memainkan Gambus, dengan modal pengetahuan yang dipunya itulah Zulkarnain dapat mengembangkan permainannya dalam memainkan viul. Mulai dengan mencari melodi-melodi lagu-lagu tradisi hingga mengembangkan teknik permainan viul dalam mengiringi musik-musik tradisi Jambi. 


\section{STUDI LITERATUR}

Penelitian ini dituntut untuk mampu menjelaskan secara kompleks dan menyeluruh tentang objek yang diteliti. Maka dalam hal ini digunakan beberapa acuan dalam penulisan baik berupa buku-buku, dokumentasi, wawancara, laporan hasil penelitian yang menyangkut dengan pengaruh dan peniruan teknik permainan biola Barat dengan viul yang dimainkan oleh Zulkarnain agar tidak terjadi duplikasi terhadap tujuan dan fokus penelitian yang berguna untuk menjaga orisinalitas kajian. Maka pertama kali yang sudah peniliti lakukan adalah penyeleksian terhadap penelitianpenelitian terlebih dahulu dengan mengambil objek yang sama ataupun yang mendekati.

Nurkholis dalam tesis yang berjudul "Lagu Seriosa sebagai Lagu Seni Indonesia: Pengaruh Musik Barat dan Musik Etnis Nusantara". Tesis ini bertujuan untuk memahami dan menganalisis pengaruh musik Barat dan musik etnis nusantara. Bentuk lagu seriosa memilik bentuk strophic, through-composed, dan song cycle, adalah bentuk musik Barat yang berkeembang di zaman Romantik (Nurkholis, 2012). Sama halnya dalam peneliti nantinya lakukan, yang akan menganalisis pengaruh apa saja yang hadir dalam setiap teknik permainan viul.

Bian Pamungkas dalam tesis yang berjudul "Hibriditas Lagu-Lagu Ranah Rasta Pada Grup Musik Ranah Rasta di Sumatera Barat". Tesis ini bertujuan untuk memahami dan menganalisis percampuran antar lagu reagge dengan lagu melayu minang. Percampuran dua budaya tersebut menimbulkan sesuatu yang dianggap baru hingga menimbulkan ambivalensi terhadap band Ranah Rasta tersebut (Pamungkas, 2017). Tesis ini sangat bisa dijadikan sebagai acuan karena dalam pembedahan secara teoritis hampir sama dengan kajia peneliti yaitu menggunakan teori poskolonial.

Benni Bestari Syarfi dalam tesisnya yang berjudul "Pengaruh Gaya Bernyanyi Tiar Ramon, Zalmon, dan Anroy's Terhadap Perkembangan Lagu Pop Minang Di Kota Padang Propinsi Sumatera Barat". Tesis mengkaji perkembangan lagu-lagu pop minang member pengaruh kepada penyanyipenyanyi muda dan selera musik masyarakat Sumatera Barat (Syarfi, 2011). Penelitian tersebut menjadi rujukan bagi peneliti yaitu sama-sama mengkaji pengaruh dominan dan subdominan.

Syafwa Turrahman dalam tesisnya yang berjudul "Pengaruh Nyanyian Krinok Terhadap Musik Pop Daerah Bungo Kabupaten Bungo, propinsi Jambi, (Kajian Musikologi)". Dalam tesis ini pengkaji melihat teknik-teknik yang sama, maupun itu dalam segi penamaan ataupun dari segi melodi-melodinya dan perkembangan musik-musik tradisi Jambi.

Muhammad Zulfahmi dalam Jurnal ISI Padangpanjang Seni Melayu Bertajuk Lintas Budaya yang berjudul "Karakteristik Biola Sebagai Mainstream Lintas Budaya Melayu Nusantara". Tulisan ini menerangkan akulturasi budaya melalui instrument biola yang masuk dari budaya Eropa ke masyarakat melayu nusantara, serta bagaimana penerimaan masyarakat itu sendiri terhadap pengaruh budaya luar yang masuk melalui politik, sosial dan budaya sehingga dapat diterima oleh masyarakat setempat (Zulfahmi, 2016). Hasil dari akulturasi tersebutlah yang menjadi suatu 
budaya yang baru sehingga menimbulkan sebuah identitas yang baru. Penelitian tersebut dapat menjadi acuan atas persamaan instrument biola yang masuk melalui pengaruh yang dibawa oleh Potugis (Eropa).

Martarosa dalam Disertasinya "Musik Gamat: Apropriasi Musik Oleh Masyarakat Bandar Pesisir Sumatera Barat," menerangkan bagaimana proses munculnya musik gamat di daerah pesisir Sumatera Barat dan perbedaan musik gamat dengan musik melayu (Martarosa; 2017). Disertasi ini membantu peneliti untuk melihat pengaruh apa saja yang masuk sehingga menjadi sebuah identitas yang baru tanpa menghilangkan kesenian yang telah ada.

Asril dalam Disertasinya "Tabuik: Pertunjukan Budaya Hibrid Masyarakat Kota Pariaman Sumatera Barat". Disertasi ini menerangkan bagaimana Tabuik yang berasal dari ritual Syi'ah dapat berkembang di tengah-tengah masyarakat Pariaman, serta terjadinya Hibridasi dari beberapa budaya yang ada dengan budaya yang datang dari luar masyarakat Pariaman itu sendiri, dan bagaimana tabuik dapat diterima oleh masyarakat Pariaman sehingga menjadi suatu identitas bagi masyarakat itu sendiri (Asril. 2016). Disertasi ini membantu peneliti untuk menjadikan bahan referensi serta menghindari persamaan dalam penulisan bagi peneliti.

Buku etude atau metode-metode untuk belajar biola secara konvensional yang peneliti gunakan untuk menjadi tinjauan pustaka, beberapa etude ini banyak digunakan sebagai bahan ajaran yang ada di ISI Padangpanjang khususnya jurusan Seni Musik. Beberapa buku etude yang digunakan adalah; H. E. Kayser; etude ini melatih teknik penggunaan bow dan penjarian pada tangan kiri, etude ini banyak digunakan bagi pemula yang ingin belajar biola. Caprices; Etude ini sebenarnya lebih digunakan untuk pemain biola yang sudah lama memainkan instrument biola, karna dalam etude ini tingkat skill yang dibutuhkan haruslah tinggi mengingat etude ini banyak melatih pembacanya untuk melatih perpindahan posisiposisi tangan kiri. Ulubione etiudyFavourite Studies, Etudes for Violin; Etude ini adalah kumpulan dari beberapa buku etude yang telah ada, dalam etude ini banyak terdapat teknik-teknik penggunaan tangan kanan dan kiri seperti; Triller, Staccato, Pizzicato, Legato, Legatura, Glissando, Martelato dan lain sebagainya. Etudeetude ini dapat menjadi tinjauan bagi peneliti untuk melihat teknik-teknik yang hadir dalam permaian viul oleh Zulkarnain, agar menjadi acuan kajian secara musikologi.

\section{METODE PENELITIAN}

Penelitian yang ini menerapkan metode penelitian Kualitatif. Metode ini merupakan suatu proses penelitian dan pemahaman yang didasarkan pada metode untuk menyelidiki suatu fenomena sosial dan masalah manusia yang bersumber dari buku-buku, wawancara, data melalui audio visual, dan karya seni itu sendiri. Teknik pengumpulan data disesuaikan dengan sifat penelitian yang digunakan penelitian kualitatif. Menurut Bogdan dan Taylor, "Metodologi kualitatif" sebagai produser penelitian yang menghasilkan data deskriptif berupa kata-kata tertulis atau lisan dari orangorang dan prilaku yang diamati (Moleong. 2010; 38). 
Sehubungan dengan ini Suwardi Endraswara mengatakan metode kualitatif merupakan metode sebuah pengamatan yang cenderung mengandalkan kekuatan indera peneliti untuk merefleksikan fenomena budaya. Pengamatan ini dipertimbangkan lebih akurat untuk melihat kebudayaan yang cenderung berubah-ubah seiring dengan pergeseran zaman (Endraswara, 2010: 28).

Jenis data dalam penelitian ini adalah kualitatif. Menurut Denzim dan Lincoln bahwa penelitian kualitatif merupakan bidang antardisiplin, lintas disiplin, dan kadang kontra disiplin. Penelitian kualitatif fokus pada pandangan naturalistik dan pemahaman interpretative (Denzim dan Lincoln, 2009: 5). Keterlibatan peneliti secara langsung melakukan observasi dan wawancara di kota Jambi adalah jembatan dalam mencapai penafsiran data-data yang dapat untuk mencapai kesimpulan dalam menjawab setiap persoalan pada fenomena yang akan diangkat ini. Data yang diperoleh berdasarkan pengamatan dan wawancara, baik itu apa yang berupa nara sumber, pelaku kesenian, masyarakat, budayawan, cendikiawan, pendukung atau penikmatnya.

Data-data kualitatif diperoleh dari hasil observasi lapangan, dan rekaman hasil wawancara yang dilakukan secara mendalam dan sifatnya terbuka. Hal tersebut didukung oleh Sugiono bahwa data kualitatif disebut juga data naturalistik, karena penelitiannya dilakukan pada kondisi yang alamiah (Natural Setting). Hal ini tersebut membuat data kualitatif dapat berupa uraian, katakata, dan ungkapan yang berkaitan dengan fenomena masyarakat dan musikologi khususnya jenis data yang akan diperlukan dalam mengkaji.

Teknik penyajian analisis data dilakukan dengan sistematis dan sesuai dengan sebuah tulisan ilmiah yang benar, sehingga dapat merangkum data-data, seperti foto sebagai pembuktian bagaimana bentuk gambar sebuah instrument viul maupun bentuk-bentuk pertunjukan itu sendiri. Peta dapat menentukan lokasi dimana daerah penelitian. Kemudian bagan yang direncanakan seperti partitur yang berguna sebagai bentuk pembuktian pembaharuan kreativitas musikalitas.

\section{HASIL DAN PEMBAHASAN}

\subsection{Hibriditas dalam Kesenian Krinok di Muaro Bungo}

Krinok adalah kesenian tradisi dari kabupaten Muaro Bungo, propinsi Jambi. Krinok merupakan salah satu jenis musik vokal (tradisional) masyarakat bungo yang lahir secara spontan yang diwariskan secara turun menurun. Banyak sekali pendapat tentang istilah krinok, Azhar MJ mengatakan bahwa krinok itu dalam bahasa kerinci yang berarti ngerawit atau gelombang, adalah cengkok lagu atau nyanyian yang dilantunkan dengan suara yang bergelombang. krinok sendiri banyak mengandung definisi, berasal dari kata melinok-linok artinya baibo-ibo. (Syawaturrahman, Pengaruh Nyanyian Krinok Terhadap Musik Pop Daerah Bungo, Propinsi Jambi. 44.) Sebagai salah satu pemain krinok, Zulkarnain juga mengatakan bahwa kesenian tersebut berasal dari kebiasaan masyarakat Pelepat, Kabupaten Muaro Bungo, provinsi Jambi. Kesenian tersebut telah ada ada sejak ia lahir dan diturunkan secara 
turun temurun yang diajarkan hanya melalui lisan.

Keunikan dari krinok sendiri telah menjadi identitas sendiri bagi masyarakat Provinsi Jambi khususnya Kabupaten Muaro Bungo. Identitas tersebut juga merupakan nilai-nilai kedaerahan yang masih bertahan hingga sekarang. Beberapa pengaruh atau perkembangan yang ada sekarang adalah, pengaruh yang selalu masuk dalam kehidupan masyarakat umum. Pengaruh zaman yang masuk melalui berbagai bentuk dan berbagai macam cara, sehingga pengaruh-pengaruh tersebut tetap masuk dengan tanggapan atau respons yang berbedabeda. Zulkarnain mengatakan, pada awalnya krinok merupakan kesenian yang dimainkan oleh solo vokal, dengan menggunakan nada-nada yang mendayu-dayu serta lirik-lirik yang menggunakan bahasa daerah. Dengan pengaruh zaman yang selalu berkembang, krinok pun juga mengalami pengaruh atas perkembangan zaman tersebut.

Perpaduan dalam suatu budaya tidak bisa dihindari lagi di negara manapun, saling keterkaitan sudah tidak bisa dilupakan begitu saja, apalagi bagi negara yang dalam statusnya menjadi "dunia ketiga". Apa yang telah dibawa oleh kolonial tersebut telah memengaruhi beberapa budaya-budaya lokal yang ada, bahkan sebagian dari kesenian-kesenian daerah yang ada hadir dan berkembang pada saat yang bersamaan dengan datangnya bangsa lain ke Indonesia. Dampak kolonial ditandai dengan serangkaian moods dan dan formasi kultural ambivalen yang mengiringi periode transisi dan translasi (Gandhi, 2014: 6).

Bahwa akibat dari penjajahan atau kolonial antara penjajah dan terjajah masing-masing tidak bisa merepresentasikan budaya mereka secara murni atau bahasa mereka secara murni. Mereka saling tergantung satu sama lain, sehingga melahirkan budaya hibriditas atau budaya campuran. Hal ini mengakibatkan identitas budaya selalu berada dalam wilayah kontradiksi dan ambivalensi atau "ruang ketiga" sehingga pengakuan terhadap sebuah hirarki "kemurnian" budaya menjadi tidak dapat dipertahankan lagi (Bhaba,1994: 24).

Meskipun bangsa kita telah diakui kemerdekaannya oleh bangsa lain dan penjajahanya pun telah berakhir, peninggalan-peninggalan pra sejarah serta kebudayaan-kebudayaan yang masih tertinggal dan terbukti keberadaannya telah menimbulkan dampak dari kolonial itu sendiri. Dampak kolonial memerlukan sebuah teori ameliorative dan therapeutic yang responsive terhadap tugas mengingat dan mengenang masa lalu kolonial (Gandhi, 2014: 10).

\subsection{Ambivalensi Permainan Viul \\ Teknik Zulkarnain}

Ambivalensi konsep besar yang mengandung konsep-konsep kecil seperti; mimikri, hibriditas, 'ruang antara', parodi, hegemoni-resistensi dan sebagainya. Dalam teori ini, Zulkarnain sebagai salah satu pemain Viul yang menjadi objek pengkaji telah memasuki ruang tersebut.

Sama-sama kita ketahui bahwa Viul atau violin bukan merupakan sebuah alat instrumen tradisi Propinsi Jambi. Dalam memainkannya violin sendiri mempunyai metode-metode yang telah dikonvensionalkan. Untuk memainkan violin yang baik dan benar menurut

telah 
dikonvensionalkan, maka dibuat bukubuku etude untuk mempelajarinya. Sebagai salah satu pemain Viul, Zulkarnain sendiri menyadari bahwa Viul sendiri bukan lah asli instrumen daerah provinsi Jambi, bahkan dia mengetahui bahwa Viul sudah menjadi bahan-bahan ajaran yang konvensional.

Permainanan violin konvensional menggunakan proses serta latihan yang telah disepakati serta diajarkan dalam kajian musikologi, teknik-teknik serta kegunaan pada instrumen pun telah diatur juga dalam proses permainan violin yang konvensional. Aturan-aturan tersebut dibuat agar dapat mempermudah dalam berproses memainkan violin, bertujuan agar seorang pemain violin mampu menguasai teknik permainan yang bagus sehingga menghasilkan bunyi yang sesuai keinginan.

Pengambilan nada pada violin berdasarkan nada yang yang telah ditentukan secara konvensional juga. Pada sebuah violin, terdapat empat buah senar yang memiliki nada-nada yang berbeda pada tiap senarnya. Urutannya E-A-D-G, nada-nada tersebut mengikuti aturan-aturan yang ada dalam musikologi. Senar A disetel terlebih dahulu ke sumber nada referensi seperti garpu tala atau, di sebagian besar orchestra, seperti oboe, biasanya hingga $440 \mathrm{~Hz}$, meskipun beberapa orchestra menyetel ke standar A lainnya seperti $442 \mathrm{~Hz}$, atau bahkan setinggi 445 atau $446 \mathrm{~Hz}$ untuk menghasilkan nada yang lebih cerah.

Aturan-aturan yang telah ada dalam melatih serta memainkan violin konvensional telah disamakan melalui buku-buku metode yang telah disepakati. Buku-buku tersebut mengajarkan teknik permainan serta penamaan dalam teknik permainannya. Untuk mempelajari teknik permainan violin yang konvensional, seorang pemain harus mengikuti aturan-aturan yang telah ada dalam buku tersebut.

Sementara itu, teknik Viul tradisi mempunyai keunikan-keunikan yang berbeda dengan teknik permainan konvensional, teknik-teknik permainan tradisi secara umum tidak dapat disamakan dengan konvensional, karena mempunyai perbedaan antara keduanya. Perbedaan-perbedaan tersebut merupakan benang merah antara tradisi dan konvensional, keduanya tidak hanya memiliki perbedaanperbedaan saja, namun juga mempunyai beberapa persamaan. Salah satu persamaan dan perbedaan tersebut merupakan sebuah dialektika kebudayaan-kebudayaan yang saling mempengaruhi yang disebabkan dengan beberapa faktor. Salah satu faktor yang mempengaruhi tersebut seperti datangnya bangsa-bangsa asing yang melibatkan dialektika kebudayaan serta sosial. Bertemunya dua kebudayaan yang berbeda, yang mana pengaruh tersebut kita temukan pada status negaranya dengan status negara "dunia ketiga".

Viul menjadi salah satu dari instrument Barat yang telah banyak menjadi instrument pengiring dalam tradisi-tradisi daerah Jambi. Tak hanya Krinok, Viul juga menjadi salah satu instrument pengiring bagi musik Melayu. yang mana instrument tersebut dimainkan dengan metodemetode dan gaya kesenian-kesenian yang ada pada kesenian tradisi tersebut.

Mengiringi Krinok, Rampi rampo dan kesenian daerah Jambi lainnya, Viul sebagai instrument pengiring memiliki teknik dan gaya yang ada 
pada kesenian tersebut. Teknik dan gaya yang hadir dalam permainan Viul merupakan imitasi dari keseniankesenian daerah yang dimainkan. Jika pada teknik Krinok ada namanya yang disebut, Cengkok, Narik dan lainnya, teknik-teknik tersebut juga dimainkan dengan instrument Viul.

Cengkok atau Grenek tidak hanya ditemukan dalam Krinok saja, dalam mengiringi musik Melayu teknik tersebut juga digunakan. Cengkok sendiri merupakan teknik yang digunakan dalam permainan Viul dengan cara menghadirkan bunyi yang mendayu-dayu mengikuti ciri khas musik Melayu tersebut.

Proses mimikri terjadi ketika Zulkarnain memainkan Viul diluar dari aturan dalam permainan violin itu sendiri. Yang pada awalnya Zulkarnain memainkan Viul dengan gaya tradisi, yang mana gaya tradisi tersebut ia mainkan ketika proses mengiring kesenian-kesenian tradisi Jambi. Seperti yang telah diterangkan diatas bahwa kesenian-kesenian tradisi tersebut awalnya dipertontonkan dengan durasi waktu yang sangat lama, sehingga para pemain tradisi bergaya memainkan Viul dengan gaya tradisi, yang mana gaya dan tekniknya tersebut dengan Lepak.

Lepak sendiri merupakan bahasa daerah yang ia gunakan untuk mengingat gaya dan teknik permainannya ini, Lepak bisa berarti Letak dalam KBBI. Salah satu alasan mengapa teknik Lepak ini digunakan oleh Zulkarnain adalah durasi yang cukup panjang dalam pertunjukannya. Maka untuk mampu memainkan Viul dalam jangka waktu yang panjang itu, Zulkarnain mengatasinya dengan menggunakan gaya dan teknik tersebut.
Lepak sendiri sebenarnya sudah menjadi ciri khas bagi pemain Viul tradisi, teknik tersebut mempunyai keunikan serta kekurangannya juga. Zulkarnain mengatakan bahwa pada saat bermain dengan posisi Lepak, jangkauan nada yang dapat ia mainkan juga terbatas. Ia juga mengatakan bahwa itu ciri khas tradisi, karena biasanya untuk memainkan lagu-lagu tradisi, nada yang digunakan hanya nada yang itu-itu saja.

Zulkarnain pun mengakui, ketika ia memainkan Viul dengan gaya konvensional, nada yang ia mainkan dapat lebih banyak serta sudah menggunakan tunning konvensional. Zulkarnain telah memainkan teknik yang konvensional, tunning yang biasanya diambil dari vokal agar mendapatkan nada dasar yang sama sudah jarang ia lakukan. Untuk menyamakan dengan vokal, permainan Viul yang dimainkan Zulkarnain sudah memainkan posisi perpindahan-perpindahan tangan kiri yang ada pada teknik permainan violin konvensional. Meskipun posisi permainan yang ia mainkan sudah menggunakan teknik yang konvensional, namun teknik-teknik yang ada pada posisi Lepak tetap ia mainkan. posisi tersebut mempermudah Zulkarnain dalam memainkan Viul untuk menjangkau nada-nada yang jarang ia gunakan saat menggunakan posisi Lepak.

Sikap ambivalen yang dilakukan Zulkarnain muncul sebagai fakta atas masuknya pengaruh-pengaruh dua budaya yang bertemu, atau menjadi hibrid. Sehingga, dalam dua pertemuan itu dua kebudayaan yang berbeda tadi dapat melebur dan memunculkan "kebaruan" yang berasal dari keduanya. Realitas yang hibrid itu, yang berproses dari dan bergerak 
bersama hubungan ulang-alik sekaligus ambivalen antara yang modern dan tradisional, yang global dan lokal, yang barat dan non barat, tak bisa (dan karena itu tak perlu) diatasi dengan penanggulangan. Setiap upaya penanggulangan adalah satu bentuk kekerasan. (Budiawan, 2010; xvii).

Ruang antara yang dilakukan Zulkarnain juga dapat dilihat dalam segi pengambilan melodi dan teknik yang dimainkannya. Karena dalam mengiringi beberapa lagu daerah, Zulkarnain mengambil teknik-teknik atau nada yang ada pada vokal tradisi tersebut. Krinok, melodi-melodi yang Zulkarnain mainkan, tidak menggunakan metode latihan serta teknik permainan yang telah dikonvensionalkan, melainkan memainkannya dengan teknik dan gayanya sendiri.

Meskipun Zulkarnain juga bisa memainkan gaya posisi permainan Viul konvensional. Teknik-teknik yang dimainkan Zukarnain merupakan teknik yang ia latih serta ia terapkan dengan menggunakan teknik-teknik tradisi. Saat memainkan Viul, nada atau tunning yang ia mainkan pada Viul ia ambil dari nada dasar dari vokalisnya. Setiap kali memainkan Viul dan bergabung dengan pemain lainnya, tunning tersebut dapat berganti nada dasar dengan alasan-alasan yang bermacam-macam. Salah satunya apabila vokalis Krinok yang pertama tidak dapat hadir atau diganti dengan vokalis lain, maka tunning yang ada pada Viul juga ikut berganti dan mengikuti nada vokal yang ada. Alasan tersebut dilakukan karena dalam mengiring Krinok, nada serta melodi yang dimainkan Viul mengikuti yang ada pada vokal Krinok.

Penggabungan antara dua budaya tersebut juga menghasilkan ruang ambivalensi. Teknik tangan kiri yang dimainkan Zulkarnain menghasilkan bunyi yang tidak ditemukan dalam praktek-praktek teori musikologi dalam mempelajari violin konvensional. Violin sendiri sudah jelas bukan alat instrument daerah Propinsi Jambi. Tapi Zulkarnain jelas-jelas memperlakukan teknik dan gayanya sendiri serta menggunakannya dengan idiom kesenian daerahnya. Ia hanya menggunakan instrument Barat namun tidak mempraktekkan dari, gaya dan metode-metode seperti yang telah diajarkan Barat. Meniru dalam segi instrument telah Zulkarnain lakukan, namun disela meniru itu ia mengejek dari tiruannya tersebut. Mengejek artiannya disini adalah sikap tidak ingin mengikuti atau melakukan hal yang diatur dalam tiruannya tersebut, dan tetap mempertahan gayanya sendiri. Akibat tarik ulur budaya yang berbeda tersebut, muncullah ruang ketiga baru yang tetap mempertahankan identitasidentitas keduanya tadi.

Teknik-teknik yang ada pada kesenian tradisi tetap melekat dalam permainan Viul Zulkarnain, walaupun musik-musik tradisi tersebut juga mengalami perkembangan, namun tidak menghilangkan musikal-musikal yang ada pada musik tradisi tersebut. Sebagai seorang pemain tradisi Zulkarnain masih mempertahankan teknik-teknik dan gaya permainan tradisi tersebut, sehingga muncul proses tarik ulur dua budaya yang berbeda, yang mana pertemuan yang konvensional dengan non konvensional memunculkan sebuah sikap yang ambivalen.

Proses-proses yang telah dilewati Zulkarnain merupakan sebuah proses yang panjang dengan pintu gerbang 
sejarah yang kompleks. Sebuah proses penggabungan dua hal yang berbeda, yang masih tetap bisa digabungkan menjadi satu. Penggabungan tersebut menghadirkan suatu hal yang baru, namun masih tetap saling mempertahankan satu sama lainnya.

Dua realitas tersebut memunculkan ruang antara atau ambivalensi yang jelas, dimana disaat pengaruh-pengaruh Zaman yang berkembang, seorang seniman yaitu Zulkarnain mencoba mempertahankan nilai-nilai daerah serta nasionalis diantara masuknya perkembanganperkembangan idiom-idiom yang datang dari luar. Akibat percampuran diantara keduanya menimbulkan ruang dua realitas yang berbeda yang dicoba digabungkan keduanya sehingga memunculkan ruang baru yang mana hasilnya menimbulkan hasil yang ambivalensi.

\section{KESIMPULAN}

Pengaruh-pengaruh masa lalu sangat penting bagi kita semua, apa yang terjadi hari ini adalah pengaruh dari hari-hari sebelumnya. Percampuran dua budaya yang berbeda hanyalah suatu proses untuk melahirkan budaya yang baru, budaya yang bertemu atas perjalanannya yang panjang, dan bertemu melalui berbagai macam cara.

Sebagai salah satu pemain tradisi, Zulkarnain telah mencoba menarik ulur dua budaya yang berbeda tersebut. Dimana percampuran dua budaya yang untuk saat ini sulit untuk kita hindari. Bagaimana kita menyikapi budaya yang telah bercampur ini agar menjadi sebuah identitas yang baru, yang mampu hadir di tengah kerasnya arus budaya yang begitu mudah masuk

Teknik-teknik yang dimainkan Zulkarnain adalah sebuah bentuk sikap menghargai kebudayaan kita sendiri dan menerima keadaan tanpa menganggap kebudayaan yang telah masuk tersebut tidak layak diterima. Ia merupakan seseorang yang mampu mengambil sisi positive dalam masuknya kebudayaan tersebut. Tidak bisa dipungkiri lagi bahwa, kedatangan bangsa-bangsa asing ke negeri ini meninggalkan bekas beserta sejarahsejarahnya. Sebagai seseorang yang mampu memanfaatkan keadaan yang seperti itu, Zulkarnain telah memunculkan wajah baru bagi kesenian tradisi Jambi. Hal yang dilakukannya pun banyak mengandung respon yang pro dan kontra. Kemunculannya pun sekarang menarik perhatian semua kalangan.

\section{DAFTAR PUSTAKA}

Salim, Agus. (2006). Teori dan Paradigma Penelitian Sosial. Yogyakarta: Tiara Wacana.

Budiawan. (2010). Ambivalensi: Poskolonial Membedah Musik sampai Agama di Indonesia. Yogyakarta: Jalasutra.

Bhaba, Homi K. Location of Culture. London: Routledge, 1994.

Pamungkas, Bian. (2017) "Musik Perlawanan Kedinamisan Dalam Budaya Hybrid". ISI Padangpanjang.

Moleong, Lexy J. (2001). Metode Penelitian Kualitatif. Bandung: PT Remaja Rosdakarya.

Endraswara, Suwardi. (2006). Metodologi Penelitian kebudayaan. Yogyakarta: Gajah Mada University Press.

Turrahman, Syafwan. (2017). "Pengaruh Nyanyian Krinok Terhadap Musik Pop Daerah Bungo, Provinsi Jambi (Kajian Musikologi)". ISI Padangpanjang. 
Denzim, Norman K., Yvanno S. Lincoln. (2009). Handbook of Qualitative Research. Yogyakarta: Pustaka Pelajar.

Hadari Nawawi. (1992). Instrumen Penelitian Bidang Sosial.
Yogyakarta: Gadjah Mada University Press.

\section{DAFTAR INFORMAN}

Zulkarnain (61 Tahun). Pemain alat music Viul. Wawancara di Jambi 11 November 2017. 